\title{
Pengembangan Desain Cincin Kinetik berdasarkan Gerak Ikan
}

\author{
Katarina Dayinta Prameswari dan Ellya Zulaikha \\ Departemen Desain Produk, Fakultas Arsitektur Desain dan Perencanaan, \\ Institut Teknologi Sepuluh Nopember, Surabaya, Indonesia \\ e-mail: katarinadayinta@gmail.com
}

\begin{abstract}
Abstrak- Secara global, terutama di negara negara maju seperti Amerika Serikat dan negara negara di Eropa perhiasan kinetik telah berkembang sejak lama. Sedangkan di Indonesia, perhiasan kinetik belum banyak berkembang. Padahal perhiasan kinetik berpotensi dan memliki pasarnya tersendiri. Lalu melalui pengamatan gerak sederhana yg sudah familiar di sekitar kehidupan masyarakat, maka dilakukan pengembangan desain cincin pada arah kinetik berdasarkan gerak ikan. Selain itu juga ikan sendiri telah memliki estetika dan gerak kinetik sendiri sebagai makhluk hidup. Penelitian ini menerapkan eksplorasi adaptasi gerak ikan pada perhiasan melalui beberapa metode analisis, yaitu analisis sistem kinetik perhiasan, analisis gerak jari dan tangan, analisis sistem, analisis gerak ikan, analisis pasar, serta analisis dan eksperimen prototype. Dengan ini menghasilkan perhiasan dengan sistem kinetik yang selaras dengan gerak ikan. Dengan ini perhiasan kinetik menjadi arah bentuk perhiasan yang baru di Indonesia.
\end{abstract}

\section{Kata kunci-Cincin, kinetik, ikan, perhiasan kinetik}

Abstract- Globally, especially in developed countries like the United States and countries in Europe, kinetic jewellery has been developing for a long time. Whereas in Indonesia, kinetic jewellery has not developed much. Though kinetic jewellery has the potential and possesses its own market. Through observing simple movements that are familiar around people's lives, a ring design is carried out in the kinetic direction based on the motion of the fish. In addition, the fish themselves have their own aesthetics and kinetic movements as living things. This study applies an exploration adaptation of fish movements to jewellery through several analytical methods, which are kinetic system of jewellery analysis, finger and hand motion analysis, system analysis, fish motion analysis, market analysis, and analysis and prototype experiments. With this it produces jewellery with a kinetic system that is in harmony with the motion of the fish. With this kinetic jewellery is the direction of the new form of jewellery in Indonesia.

Keywords - Ring, kinetic, fish, kinetic jewellery

\section{PENDAHULUAN}

Di Indonesia, perhiasan kinetik bukanlah bentuk perhiasan yang umum. Perhiasan yang dijumpai di Indonesia pada umumnya merupakan perhiasan statis. Dalam hal ini perhiasan bertumpu penuh bentuk dan estetika dari perhiasan tersebut. Perhiasan kinetik yang ada di Indonesia terbatas. Jika kita melihat secara global, di luar Indonesia perhiasan kinetik telah berkembang dengan pesat. Diluar Indonesia berbagai jenis perhiasan kinetik yang telah di pamerkan.

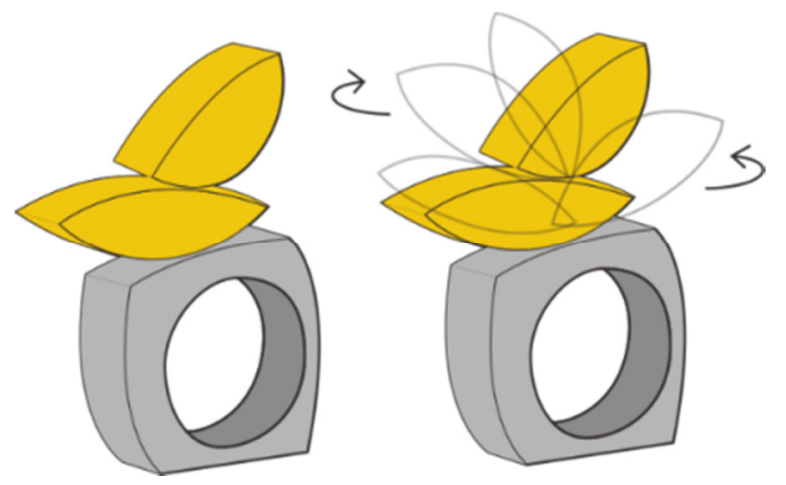

Gambar 1. Model cincin kinetik [1].

Perkembangan teknologi perhiasan kinetik bergerak pesat. Hal ini di ikuti oleh perkembangan jaman dimana masyarakat terus menginginkan suatu kebaruan. Generasi millennial sendiri, yang merupakan target pasar seluruh perusahaan perhiasan untuk ke depan, memiliki kecenderungan untuk mengedepankan teknologi dalam berbelanja. Generasi millennial (kelahiran tahun 1980 1995) merupakan pasar utama karena seperti yang diketahui, pada tahun 2018 ini, Menurut data BPS, saat ini $50 \%$ dari penduduk usia produktif berasal dari generasi millennial dan pada tahun 2020 hingga 2030 diperkiraan jumlahnya mencapai $70 \%$ dari penduduk usia produktif. Apalagi secara populasi, menurut hasil perhitungan, pada tahun 2020 populasi generasi millennial kelas menengah urban mencapai 35 juta jiwa atau $13 \%$ dari populasi. Dalam sudut pandang marketing, jumlah tersebut merupakan ceruk pasar yang cukup besar dan menggiurkan [2].

Mengenai sifat pada umumnya, generasi millenial lebih akan menghabiskan uang untuk pengalaman (experience) di bandingkan untuk barang barang material, maka dari itu perlu strategi tersendiri untuk perusahaan perhiasan. Hal ini diikuti oleh ketergantungan generasi millennial pada media social. Menurut fashion stylist Caren Delano, Generasi millenial menyukai desain aksesori yang bergaya modern, simpel, dan unik. Hal yang sama juga diungkapkan oleh 
narasumber, Direktur Kreatif Produsen Emas, Erwin Suganda. Dia menyebut, tampilan perhiasan yang simpel, kekinian, dengan desain out of the box adalah yang dicari konsumen anak muda [3].

Perusahan besar perhiasan seperti PT. UBS memiliki keharusan untuk mengikuti perkembangan teknologi ini. Sebagai perusahaan perhiasan emas besar di Indonesia, dibutuhkan inovasi bentuk dan kesan yang baru. Hal ini bisa disalurkan dalam bentuk perhiasan kinetik. Perusahaan ini sendiri telah mengeluarkan beberapa koleksi perhiasan kinetik, seperti Flying Butterfly. Menurut narasumber, produk Flying Butterfly keluaran perusahaan ini, laku terjual di kalangan anak muda.

Maka dari itu dengan perhiasan kinetik ini dapat menjadi produk icon dari perusahaan ini. Bentuk kinetik ini juga dapat menjadi spesialisasi sendiri sebagai perusahaan emas terkemuka di Indonesia.

\section{METODE}

Studi yang dilakukan pada penelitian ini diawali dengan analisis Sistem Kinetik Perhiasan, untuk mengetahui perhiasan perhiasan yang ada, kinetik dan sistemnya. Lalu Analisis Gerak Jari Dan Tangan, untuk mengetahui karakteristik kegiatan jari dan tangan sebagai sumber gerak. Lalu Analisis Sistem, untuk mengetahui bentuk bentuk perhiasan kinetik maupun tidak yang sudah ada. Lalu Analisis Gerak Ikan, untuk mengetahui karakteristik kegiatan hewan yang dapat diterapkan pada gerak kinetik cincin. Analisis Pasar, untuk mengetahui dan menyesuaikan desain dengan selera konsumen (pasar). Analisis Dan Eksperimen Prototype, dilakukan pembuatan prototype untuk menguji keberhasilan gerak dan kelayakan dan perhiasan tersebut. Hal ini dilakukan karena sistem kinetik perlu diuji secara fisik untuk mengetahui kesalahan yang mungkin terjadi.

\section{HASIL DAN PEMBAHASAN}

\section{A. Analisis sistem kinetik perhiasan}

Perhiasan kinetik sendiri masih belum memiliki arti secara resmi. Kata kinetik memiliki arti berhubungan dengan gerak (kbbi) [4] atau (dari sebuah karya seni) tergantung pada gerakan untuk efeknya (English Oxford Dictionaries) [5]. Melalui pengertian ini dapat disimpulkan bahwa perhiasan kinetik adalah perhiasan bergerak atau perhiasan yang bergantung pada gerakan. Pengertian tersebut membuat bentuk dari perhiasan kinetik cukup luas. Melalui benchmarking perhiasan kinetik sudah ada dapat dibagi menjadi seperti seperti bagan berikut:

Dalam penelitian ini perhiasan kinetik difokuskan pada gerak perpetual motion dan mechanical movement; design to automatically moves. Hal ini di pertimbangkan karena mechanical movement; design to be moved kurang kinetik dan lebih masuk ke kategori perhiasan modular atau transformasi, tidak berfokus pada gerakannya [6]. Cincin, merupakan lingkaran kecil yang dipakai pada jari. Dalam hal ini cincin beragam bentuknya. Hal ini juga menunjukkan bahwa cincin dapat dipakai tidak hanya untuk satu jari, tetapi dapat lebih dalam satu perhiasan. Cincin yang digunakan untuk lebih dari satu jari pada umumnya disebut Knuckle ring.

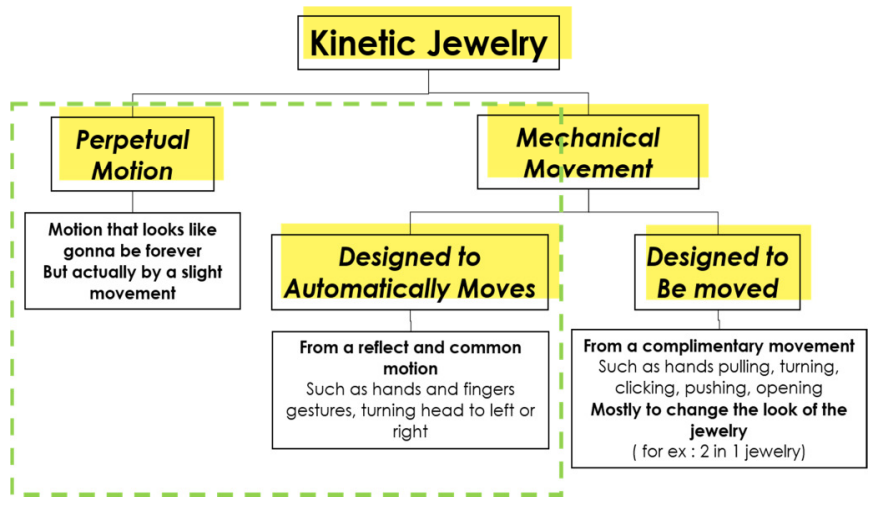

Gambar 2. Bagan perhiasan kinetik.

\section{B. Analisis gerak jari dan tangan}

Sebuah gerakan memerlukan sumber energi. Tanpa sumber energi tambahan seperti listrik maupun baterai, perhiasan kinetik bergerak dengan sumber gerak tubuh. Analisis ini dilakukan untuk menentukan sumber gerak untuk perhiasan kinetik yang akan dihasilkan. Pemakaian cincin ditujukan untuk jari dan tangan, maka dari itu dilakukan analisis gerak jari dan tangan untuk menentukan arah gerak cincin kinetik ini. Analia gerak jari dan tangan dapat dilihat pada Tabel 1 dan Tabel 2.

Tabel 1. Gerak Jari dan Kegiatannya

\begin{tabular}{|c|c|}
\hline Gerak Jari & Kegiatan \\
\hline 1. & $\begin{array}{l}\text { Mengetik, menunjuk, } \\
\text { menarik, menggenggam, } \\
\text { meremas, meng-tap } \\
\text { handphone }\end{array}$ \\
\hline 2. & $\begin{array}{l}\text { Mengetik, menunjuk, } \\
\text { menarik, menggenggam, } \\
\text { meremas, meng-tap } \\
\text { handphone }\end{array}$ \\
\hline & $\begin{array}{l}\text { Swipe hanphone, memberi } \\
\text { tanda, meregangkan tangan }\end{array}$ \\
\hline 3. & \\
\hline
\end{tabular}

Dari kedua tabel tersebut selanjutnya dapat dilihat kegiatan yang yang secara reflek akan dilakukan oleh manusia pada umumnya. Dengan penggunaan kegaitan yang reflek, memberikan kesan seakan perhiasan bergerak sendiri. Selain itu perhiasan akan sering bergerak sehingga memaksimalkan unsur kinetik pada perhiasan tersebut. 
Tabel 2. Gerak tangan dan kegiatannya

Mengetik, memberi tanda,
mengipas, memanggil,
menyapa, membersihkan

Pada penelitian ini, difokuskan pada gerak jari nomor 2 (Tabel 1), dimana jari bergerak atas dan bawah dengan sendi ruas jari yang merupakan sendi engsel. Gerakan ini menghasilkan gerak linear horisontal, gerak satu arah atas dan bawah.
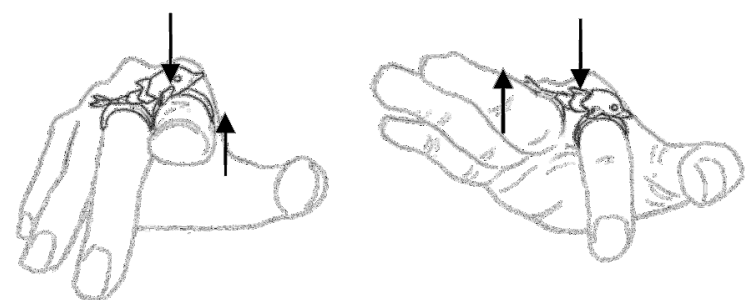

Gambar 3. Gerak bergantian antar jari

\section{Analisis sistem}

Melalui gerak linear horisontal yang dihasilkan gerak nomor 2 (Tabel 1). Jika dilakukan bergantian antar jari (gambar 3), menghasilkan perbedaan ketinggian yang menghasilkan kesan ombak pada punggung tangan.

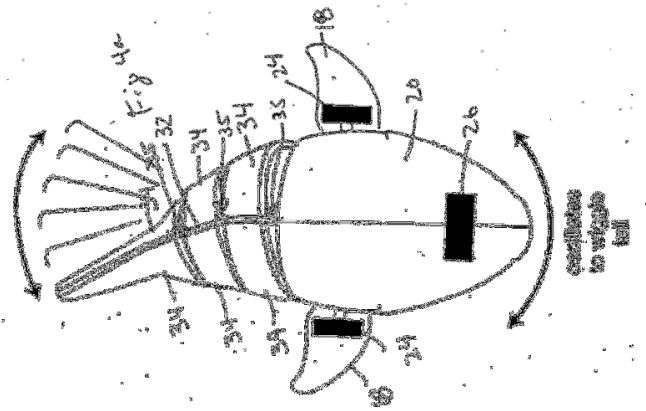

Gambar 4. Mainan Interaktif Ikan [7].

Melalui gerak bergantian jari ini, dihasilkan sistem gerak ombak yang mirip dengan gerak renang ikan. Sistem engsel dihasilkan berdasarkan inspirasi bentuk mainan interaktif ikan [7] seperti dapat dilihat pada Gambar 4.

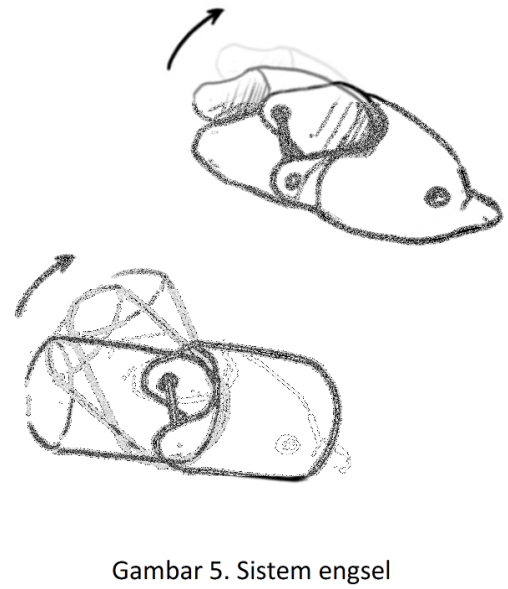

Dari bentuk mainan tersebut secara sederhana dihasilkan bentuk engsel mirip dengan gerakan diatas sepertidapat dilihat pada Gambar 5.
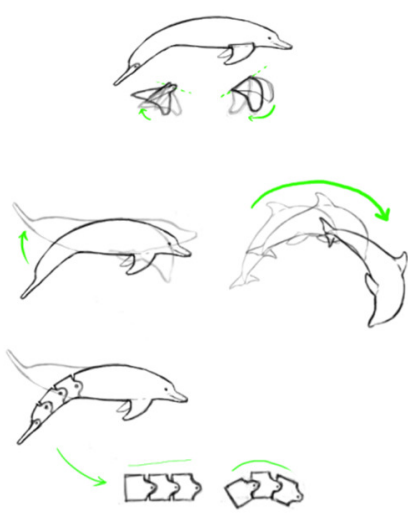

Gambar 6. Analisis gerak ikan.

\section{Analisis gerak ikan}

Diikuti dengan analisis gerak renang ikan, dalam hal ini gerak ikan koi dan ikan lumba lumba, bahwa ikan bergerak seperti dapat dilihat pada Gambar 6. 


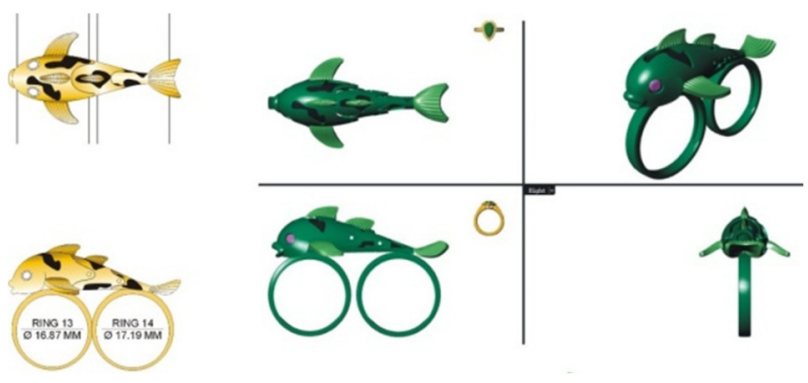

Gambar 7. Desain prototype 1 cincin Koi

Untuk menghasilkan kesan gerak lengkung yang dihasilkan ikan saat berenang, dilakukan pembagian bagian bagian tubuh sehingga tubuh ikan dapat melengkung dan bergerak melalui engsel yang menyatukannya. Dalam desain ini ingin mengangkat gerak renang ikan yang dapat diterapkan pada perhiasan sehingga seakan akan perhiasan menjadi hidup (Gambar 7).
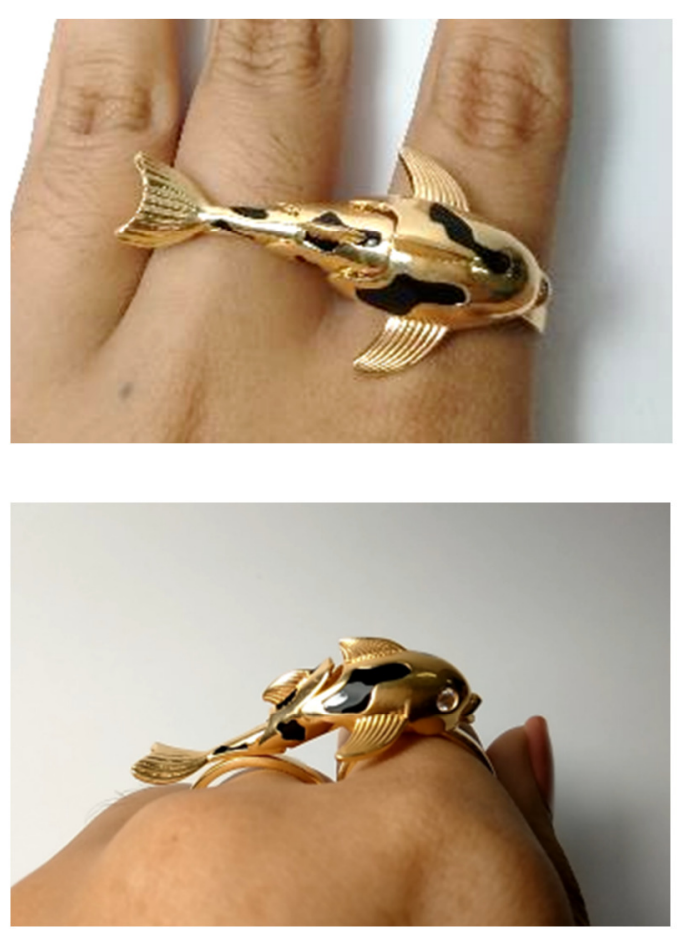

Gambar 8. Prototype 1 cincin Koi

\section{E. Analisis konsumen}

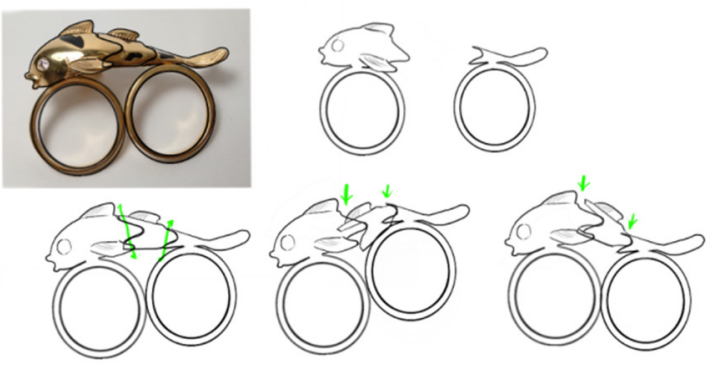

Gambar 9. Analisis kelemahan prototype 1 cincin Koi.
Pemilihan jenis ikan Koi untuk desain prototype pertama dilakukan berdasarkan data pasar milik PT.UBS dimana peminat perhiasan berbentuk ikan berjenis Koi cukup tinggi. Selain itu, corak pada ikan Koi yang dapat diterapkan pada perhiasan memberikan bentuk yang membedakan dengan ikan ikan lain. Dengan ini pengguna dapat langsung tahu bahwa cincin tersebut adalah ikan Koi.

Selanjutnya ikan Lumba lumba digunakan sebagai desain prototype kedua karena terdapat permintaan permintaan bentuk lumba lumba. Hasil ini ini didapati dari dilakukannya user testing. User testing dilakukan dengan meminjamkan prototype untuk dipakai pada keseharian selama tiga hari oleh pengguna. Pada user testing ini, dihasilkan tidak hanya pendapat pengguna, tetapi juga pendapat orang orang yang berada disekitar pengguna, bagaimana respon yang dihasilkan dari orang lain. Respon orang lain ini penting karena perhiasan merupakan salah satu cara untuk memberikan kesan dan mengekspresikan diri pada orang lain.

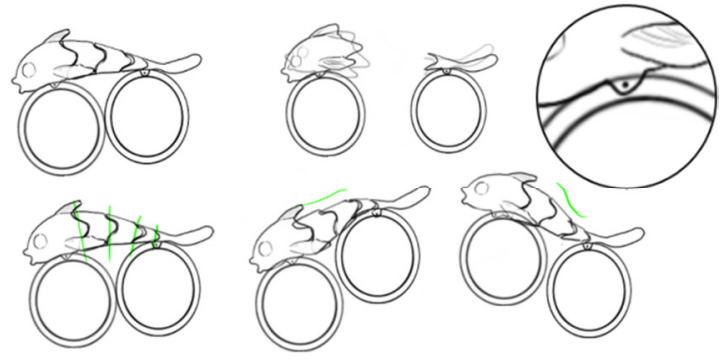

Gambar 10. Solusi 1 dan 2 untuk kelemahan protoype 1 cincin

Melalui user testing ini didapati beberapa saran, baik dari pengguna maupun orang disekitarnya, untuk diproduksinya bentuk ikan lain yaitu lumba lumba. Diluar itu juga, berdasarkan data pasar milik PT.UBS, lumba lumba juga termasuk bentuk yang cukup laku dan diminati.
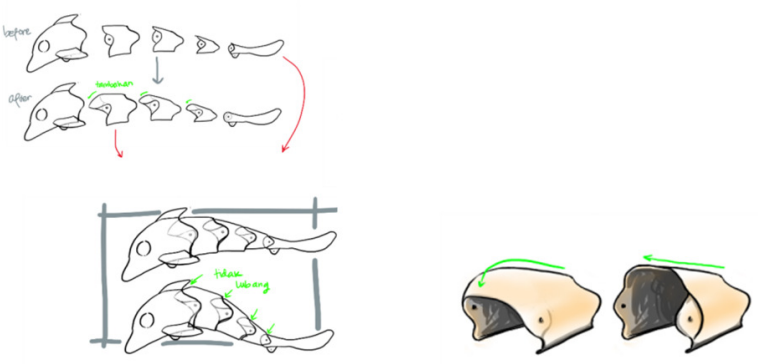

Gambar 11. Solusi 3 Kelemahan Protoype 1 Cincin Koi

\section{$F$. Analisis dan eksperimen/pengujian prototype}

Melalui proses produksi, dihasilkan prototype cincin seperti dapat dilihat pada Gambar 8.

Dari pengujian prototype tersebut, ditemukan beberapa kelemahan. Bentuk cincin ikan tersebut terbagi menjadi 3 (tiga) bagian, kepala, badan dan ekor, dimana ekor dan badan masing masing menyatu dengan cincin. Tiap bagian menjadi satu sistem engsel. Saat prototype dipakai dan digerakan, didapati bahwa gerakan masih kaku dan bagian 
sambungan engsel terlihat patah. Gerakan ikan kurang alami (Gambar 9).

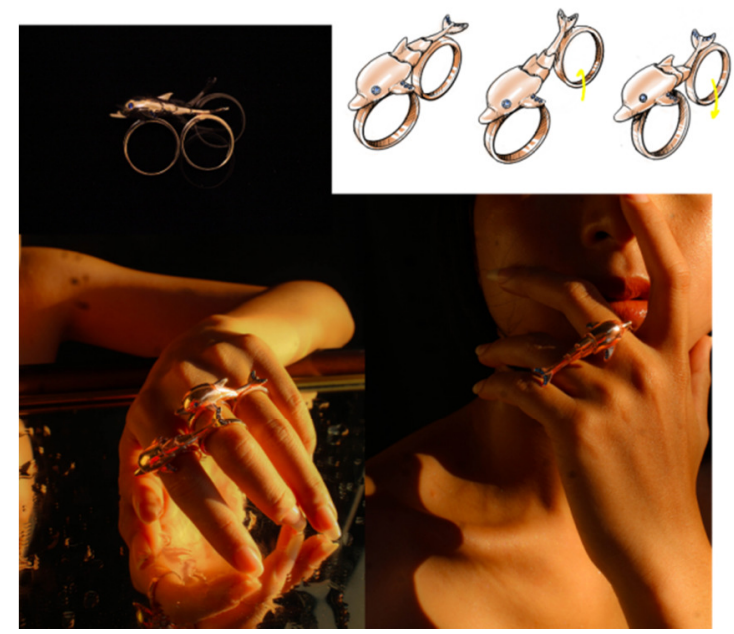

Gambar 12. Prototype 2 cincin Dolphin.

Berdasarkan kelemahan yang telah ditengarahi tersebut selanjutnya dilakukan perubahan bentuk untuk memperbaiki kelemahan-kelemahan tersebut (Gambar 10):

1. Dilakukan penambahan bagian, dimana ada dibagi menjadi 4 (empat) bagian. Hal ini dilakukan agar mengahasilkan bentuk lengkung tubuh ikan yang lebih halus.

2. Bagian yang menyatu dengan cincin dipisahkan menjadi bagian tersendiri dan bagian penggabungan diberikan engsel tambahan. Hal ini dilakukan agar tubuh ikan bergerak lebih bebas sehingga terlihat lebih alami. Selain itu juga memudahkan penyesuaian, dimana jari memiliki ukuran yang berbeda beda. Dengan dipisahkan, produksi menjadi mudah sesuai dengan ukuran cincin pembeli.

3. Dilakukan perubahan bentuk tiap bagian, terutama bagian selain kepala. Hal ini dilakukan agar ketika digerakan, bagian patahan tertutup dan tidak lagi memberi kesan menyatu (Gambar 11).

Setelah perbaikan desain dengan solusi solusi diatas, dihasilkan prototype kedua cincin kinetik. Untuk prototype 2 ini objek diubah dari ikan Koi menjadi ikan Lumbalumba. Berikut hasil prototype kedua yaitu cincin Dolphin (Gambar 12).

\section{KESIMPULAN}

Berdasarkan data dan pembahasan mengenai analisis cincin. Kesimpulan yang dapat diambil adalah sebagai berikut:

Melalui gerak linear horisontal dan paten mainan interaktif ikan, di hasilkan sistem engsel yang dapat di terapkan pada cincin. Gerak tersebut menghasilkan bentuk cincin ikan yang dapat bergerak seperti berenang ketika menggerakkan jari. Melalui analisa pasar diketahui bahwa hewan yang diminati adalah ikan Koi dan lumba-lumba sehingga desain yang dihasilkan berdasarkan bentuk ikan ikan tersebut

\section{UCAPAN TERIMA KASIH}

Penulis mengucapkan terima kasih kepada Direktur Jewelry Design PT.UBS dan Kepala Departemen Desain Produk ITS.

\section{DAFTAR PUSTAKA}

[1] Berger, M, Michael Berger Kinetischer Schmuck. Diambil kembali dari http://www.atelierberger.de/kollektion/ (2019)

[2] Ali, Hasanuddin., Lilik Purwandi, "The Urban MiddleClass Millenials Indonesia: Financial and Online Behaviour", Jakarta Selatan: PT. Alvara Strategi Indonesia (2017)

[3] UBS Lifestyle. (t.thn.). Diambil kembali dari https://ubslifestyle.com/

[4] Indonesia, K. B. (t.thn.). Kamus Besar Bahasa Indonesia. Diambil kembali dari https://kbbi.web.id/kinetik

[5] English Oxford Dictionaries. (t.thn.). Diambil kembali dari https://en.oxforddictionaries.com/definition/kinetic

[6] Maryani, D., "Perhiasan Simpel Unik Favorit Millenial", Diambil kembali dari Indopos: https://indopos.co.id/read/2018/02/22/128384/perhiasan -simpel-unik-favorit-millenial (2018, Februari 22)

[7] Rehkemper, J., Rehkemper, S., Kratz, R., \& Wilson, J, Paten No. US20060228982A1 (2005)

[8] Stuller, "The Basics of Jewelry Terminology and Design Guide", Los Angeles: Stuller Inc (2012) 